\title{
ARTICLE OPEN \\ First maintenance therapy for COPD in the UK between 2009 and 2012: a retrospective database analysis
}

\author{
David Price ${ }^{1}$, Marc Miravitlles ${ }^{2}$, lan Pavord ${ }^{3}$, Mike Thomas ${ }^{4}$, Jadwiga Wedzicha ${ }^{5}$, John Haughney ${ }^{1}$, Katsiaryna Bichel ${ }^{6}$ and Daniel West ${ }^{6}$
}

Clinical guidelines recommend long-acting bronchodilators as first maintenance therapy for chronic obstructive pulmonary disease (COPD), with inhaled corticosteroids (ICS) reserved for patients with more severe disease and exacerbations. The aim of this analysis was to examine real-life prescribing of first maintenance therapy for COPD in the UK. Data were extracted from the UK Optimum Patient Care Research Database for patients with a first prescription for COPD maintenance therapy between 2009 and 2012 and a diagnosis of COPD at or before the date of the first prescription for COPD maintenance therapy. Routine clinical data including demographics, disease history and symptoms, comorbidities, therapy, hospitalisation rate and exacerbation rate were collected and used to characterise patients stratified by disease severity and Global Initiative for Chronic Obstructive Lung Disease (GOLD) group (A-D). The analysis population included 2,217 individuals (55.4\% male, 45.2\% smokers). Long-acting muscarinic antagonists (LAMA) as monotherapy were prescribed as first maintenance therapy for $40.2 \%$ of patients. ICS were prescribed as ICS/long-acting beta-agonists combination for $29.1 \%$ of patients or as monotherapy for $15.5 \%$. ICS (alone or in combination) were prescribed to $>40 \%$ of patients in each GOLD group. ICS-containing regimens were prescribed to patients with a history of pneumonia and comorbid conditions for whom the risks of ICS therapy may outweigh the benefits. The clinical reality of prescribing indicates that ICS are often prescribed outside current guideline recommendations for many patients newly diagnosed with COPD in the UK. Encouragingly, LAMAs are increasingly being prescribed as first maintenance therapy for these patients.

npj Primary Care Respiratory Medicine (2016) 26, 16061; doi:10.1038/npjpcrm.2016.61; published online 3 November 2016

\section{INTRODUCTION}

Over one million individuals in the UK are currently living with chronic obstructive pulmonary disease (COPD), with an estimated 25,000 deaths each year from the disease. ${ }^{1}$ COPD is a complex condition with both pulmonary and extrapulmonary manifestations necessitating a holistic approach to the evaluation and management of patients. In the UK, patients with COPD are largely managed in the primary care setting. ${ }^{2}$ The National Institute for Health and Care Excellence (NICE) guidelines for the assessment and management of patients with COPD advocate a multidimensional approach in agreement with recommendations from the Global Initiative for Chronic Obstructive Lung Disease (GOLD). ${ }^{3,4}$ Broadly, the goals of treatment are to relieve the symptoms of breathlessness, reduce the frequency and severity of exacerbations, improve health-related quality of life, improve exercise capacity and slow disease progression (through smoking cessation).

UK NICE guidelines recommend bronchodilators as initial therapy comprising short-acting beta-agonists or short-acting muscarinic antagonists. For those patients with stable COPD who remain breathless despite using short-acting bronchodilators, long-acting muscarinic antagonists (LAMAs) or long-acting beta-agonists (LABAs) are recommended as maintenance therapy if the forced expiratory volume over $1 \mathrm{~s}\left(\mathrm{FEV}_{1}\right)$ is $\geqslant 50 \%$, and LABA+inhaled corticosteroid (ICS) or LAMA for those with FEV 1 $<50 \%$ predicted. ${ }^{4}$ These recommendations are in line with GOLD recommendations, which suggest that inhaled ICS therapy should be reserved as an option for those in GOLD groups $C$ or $D .^{3}$
The role of ICS in the management of patients with COPD is still debated. These agents have not been shown to prevent disease progression or reduce mortality in controlled clinical trials and are generally prescribed with the aim of reducing the frequency or severity of exacerbations. ${ }^{5}$ However, many of the inflammatory processes found in individuals with COPD are of a type not amenable to ICS therapy and it remains unclear which patients can be expected to gain meaningful benefit. ${ }^{6}$ An additional challenge when managing patients with COPD is that comorbidities are common and these can impact prognosis. ${ }^{3}$ Comorbid conditions may also influence treatment decisions, particularly with respect to ICS therapy which has been shown to increase the risk for infective comorbidities and be associated with the presence of non-infective comorbidities. ${ }^{7}$ Given these challenges and unanswered questions, it is perhaps unsurprising that there are data to suggest that clinical practice does not always reflect current clinical guidelines in the $\mathrm{UK}^{8}$ and other European countries. ${ }^{9-12}$

We reported a previous evaluation of prescribing patterns in the UK among 24,957 patients with moderate airflow limitation $\left(\mathrm{FEV}_{1} \geqslant 50 \%\right.$ to $\left.<80 \%\right)$ COPD, which corresponds to GOLD stage $1{ }^{13}{ }^{13}$ In this large cohort of patients, around half were receiving an ICS alone or in combination with a $L A B A$ or a $L A B A$ and a LAMA, a treatment approach not in line with either NICE recommendations or GOLD guidelines. To extend these observations regarding treatment of all patients with COPD, we evaluated treatment selection (prescribing) for patients commencing first maintenance therapy for COPD in the UK.

${ }^{1}$ Centre of Academic Primary Care, University of Aberdeen, Aberdeen, UK; ${ }^{2}$ Department of Pneumology, Hospital Universitari Vall d'Hebron, Ciber de Enfermedades Respiratorias

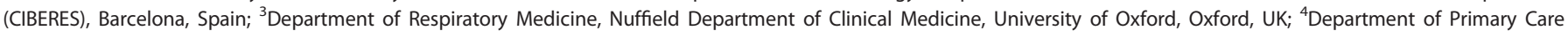
Research, University of Southampton, Southampton, UK; ${ }^{5}$ Airway Disease Section, National Heart and Lung Institute, Imperial College, London, UK and ${ }^{6}$ Research in Real-Life Ltd, Cambridge, UK.

Correspondence: D Price (david@rirl.org)

Received 27 May 2016; accepted 19 June 2016 
This approach was undertaken in order to investigate whether treatment selection for first maintenance therapy aligns with current local and international treatment guidelines with respect to patient characteristics, medical history, disease severity and the presence of comorbidities, particularly with respect to ICS use.

\section{RESULTS}

The population for analysis comprised 2,217 individuals with a diagnosis of COPD (confirmed by a post-bronchodilator $\mathrm{FEV}_{1} /$ forced vital capacity $<0.7$ for $83 \%$ of patients), $55.4 \%$ of whom were male, $45.2 \%$ were smokers and $46.9 \%$ were ex-smokers. Figure 1 illustrates the derivation of the patient cohort for the current analyses. The majority of patients had received their initial diagnosis of COPD and first major therapy for COPD when they were aged $\geqslant 60$ to $<75$ years of age $(54.0 \%$ and $53.2 \%$, respectively; Table 1 ).

\section{First maintenance therapy}

The most commonly prescribed first maintenance therapy for COPD was a LAMA ( $40.2 \%$ of patients) followed by an ICS+LABA combination ( $29.1 \%$ of patients). ICS monotherapy was prescribed as first COPD maintenance therapy for $15.5 \%$ of patients.

Figure 2 details the prescribing pattern for the first major therapy class by GOLD group. Among patients initially assessed as GOLD group A or B, 385/803 (47.9\%) and 226/461 (49.0\%), respectively, received an initial prescription of an ICS alone or in combination with a bronchodilator. ICS-containing regimens were prescribed to $>40.0 \%$ of patients in each GOLD group.

Comorbidities, pneumonia history and prescribing patterns Among the 2,217 patients newly diagnosed with COPD before or at their first major therapy prescription, 6.8\% $(n=150)$ had a history of pneumonia, $11.4 \%$ had osteoporosis $(n=252), 15.9 \%$ had chronic kidney disease $(n=353), 17.2 \%$ had asthma $(n=381)$ and $23.6 \%(n=524)$ had diabetes (Type 1 or Type 2).

These comorbidities were apparent among those with GOLD group A and B COPD (osteoporosis 10.5\% (84/803) and 14.3\% (66/461), chronic kidney disease $14.2 \%(114 / 803)$ and $20.8 \%$ (96/461) and diabetes (Type 1 and Type 2) 19.1\% (153/803) and $28.9 \%$ (133/461), respectively; Figure 3). In all, 5.5\% (44/803) and $5.4 \%(25 / 461)$ in GOLD groups A and B, respectively, had a history of pneumonia.

An ICS was prescribed in 255/381 (67\%) patients with asthma, either as monotherapy $(25 \%)$ or in combination with a bronchodilator (42\%). Among the 150 patients with a history of pneumonia prior to the first major therapy prescription for COPD, $76(50.7 \%)$ were initially prescribed an ICS-containing regimen (Figure 4). ICS-containing regimens were also prescribed as first maintenance therapy for $134 / 252$ (53.2\%) of those with comorbid osteoporosis and 270/524 (51.5\%) of those with comorbid diabetes (Type 1 and Type 2).

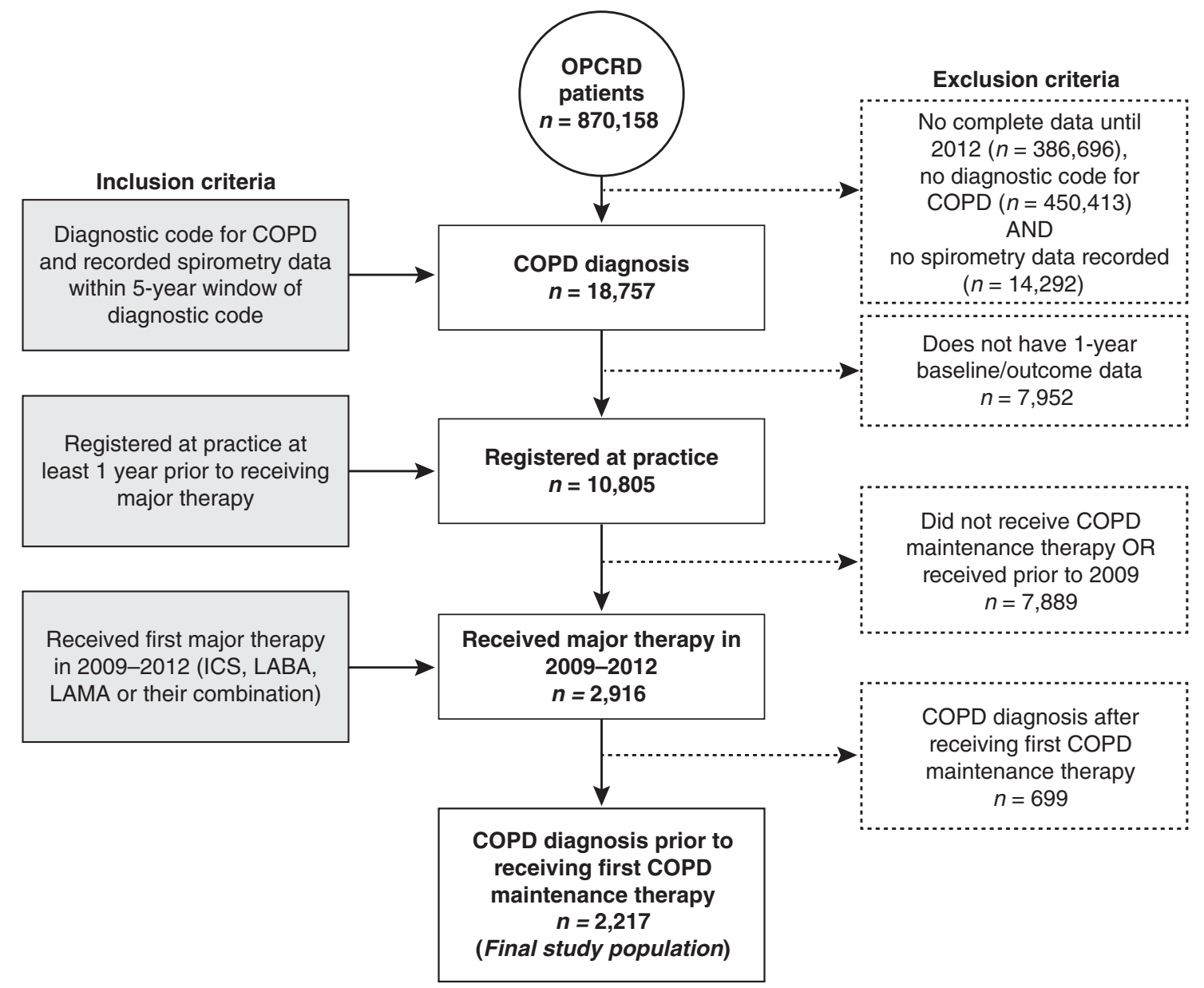

Figure 1. Consort diagram. COPD, chronic obstructive pulmonary disease; ICS, inhaled corticosteroid; LABA, long-acting beta-agonist; LAMA, long-acting muscarinic antagonist; OPCRD, Optimum Patient Care Research Database. 
Table 1. Baseline demographics and disease characteristics

\begin{tabular}{|c|c|}
\hline Variable, N (\%) & $\begin{array}{l}\text { Total study population } \\
\qquad(\mathrm{N}=2,217)\end{array}$ \\
\hline \multicolumn{2}{|l|}{ Age at initial COPD diagnosis } \\
\hline$<60$ years & $497(22.4)$ \\
\hline$\geqslant 60$ to $<75$ years & $1,197(54.0)$ \\
\hline$\geqslant 75$ years & $523(23.6)$ \\
\hline \multicolumn{2}{|l|}{ Age at first major therapy } \\
\hline$<60$ years & $403(18.2)$ \\
\hline$\geqslant 60$ to $<75$ years & $1,179(53.2)$ \\
\hline$\geqslant 75$ years & $635(28.6)$ \\
\hline $\begin{array}{l}\text { Time from COPD diagnosis to first prescription } \\
\text { for COPD maintenance therapy, median years } \\
\text { (range) }\end{array}$ & $0.4(0-2.6)$ \\
\hline Male gender & $1,229(55.4)$ \\
\hline \multicolumn{2}{|l|}{ Smoking status } \\
\hline Non-smoker & $174(7.9)$ \\
\hline Current smoker & $1,002(45.2)$ \\
\hline Ex-smoker & $1,040(46.9)$ \\
\hline Unknown & $1(<0.1)$ \\
\hline \multicolumn{2}{|l|}{ GOLD COPD severity post-bronchodilator } \\
\hline 1: $\mathrm{FEV}_{1} \geqslant 80 \%$ predicted & $204(11.1)$ \\
\hline 2: $50 \% \leqslant \mathrm{FEV}_{1}<80 \%$ predicted & $1,038(56.4)$ \\
\hline 3: $30 \% \leqslant \mathrm{FEV}_{1}<50 \%$ predicted & $499(27.1)$ \\
\hline 4: $\mathrm{FEV}_{1}<30 \%$ predicted & $99(5.4)$ \\
\hline Unconfirmed COPD $\left(\mathrm{FEV}_{1} / \mathrm{FVC}<0.7\right)$ & $377(17.0)$ \\
\hline \multicolumn{2}{|l|}{ GOLD group ${ }^{\mathrm{a}}$} \\
\hline A & $803(36.9)$ \\
\hline B & $461(21.2)$ \\
\hline C & $516(23.7)$ \\
\hline D & $396(18.2)$ \\
\hline Unknown & $41(1.8)$ \\
\hline \multicolumn{2}{|l|}{ Moderate and severe exacerbation rate } \\
\hline 0 & $1,177(53.1)$ \\
\hline 1 & $598(27.0)$ \\
\hline 2 & $280(12.6)$ \\
\hline$\geqslant 3$ & $162(7.3)$ \\
\hline \multicolumn{2}{|l|}{ First COPD maintenance prescription } \\
\hline ICS & $344(15.5)$ \\
\hline ICS+LABA & $646(29.1)$ \\
\hline ICS+LAMA & $12(0.5)$ \\
\hline ICS+LABA+LAMA & $129(5.8)$ \\
\hline LAMA & $891(40.2)$ \\
\hline LABA & $186(8.4)$ \\
\hline $\mathrm{LAMA}+\mathrm{LABA}$ & $9(0.4)$ \\
\hline
\end{tabular}

COPD, chronic obstructive pulmonary disease; $\mathrm{FEV}_{1}$, forced expiratory volume over $1 \mathrm{~s}$; FVC, forced vital capacity; GOLD, Global Initiative for Chronic Obstructive Lung Disease; ICS, inhaled corticosteroid; LABA, longacting beta-agonist; LAMA, long-acting muscarinic antagonist; MRC, Medical Research Council.

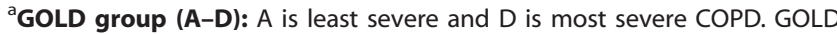
group determined according to MRC score. Both routine medical practice recorded and patient questionnaire MRC scores were used with the most recent score taking precedence. The category 'Unknown' was assigned to patients with no MRC score available.

${ }^{\mathrm{b}} 1$ year prior to/at first COPD maintenance therapy prescription, defined as an unscheduled hospital admission/A\&E attendance for COPD (definite code) or lower respiratory-related events (i.e., with a lower respiratory read code); OR lower respiratory tract infections treated with antibiotics (definite code); OR acute use of oral steroids (definite plus possible courses); OR antibiotics use with a lower respiratory read code within a \pm 5 day window.

\section{DISCUSSION}

Main findings

The data presented here suggest that bronchodilator therapy is increasingly prescribed as first maintenance therapy for patients newly diagnosed with COPD in the UK. However, a relevant proportion of patients continue to receive first maintenance therapy that is not consistent with current recommendations with respect to the prescription of ICS.,4

Interpretation of findings in relation to previously published work The results presented here for the UK are consistent with observations in other countries including France, Italy, Norway, Spain, Switzerland and the USA..$^{9-12,14-17}$ Furthermore, baseline demographic data in the current study are comparable to those in similar studies, including much larger real-world populations of patients with COPD. ${ }^{18,19}$ Of particular concern is the observation that $15.5 \%$ of patients were prescribed an ICS monotherapy as their first maintenance therapy despite the lack of data, or a licensed indication, to support the use of ICS as monotherapy in COPD at any severity level. ${ }^{16}$

Higher-dose ICS therapy has been shown to increase the risk for side effects, including pneumonia and fractures. However, if the benefits outweigh the associated risks, it may be in a patient's best interest to receive ICS therapy and this should be decided on a patient-by-patient basis. $^{20-22}$ Importantly, the inappropriate prescribing of ICS exposes patients to the risk of the potentially serious side effects of treatment without the counterbalance of an evidence-based efficacy benefit. Our observations of an overuse of ICS as first maintenance therapy are consistent with a recent cross-sectional evaluation of ICS use among patients with COPD across 41 primary care practices in London. ${ }^{17}$ The authors found that ICS were widely prescribed against current recommendations, including for $38.0 \%$ of patients classed as GOLD stage I or II according to the GOLD 2011 guidelines and 33.6\% of those classed as GOLD stage III or IV but without exacerbations. ${ }^{17}$ Moreover, $>40.0 \%$ of those classed as GOLD stage IV, for whom ICS therapy is recommended in current guidelines, were not prescribed these agents. The results of our study confirm and extend the observations reported by White et al. ${ }^{17}$ and show that ICS are widely and inappropriately prescribed to patients with COPD from the time of diagnosis regardless of GOLD stage. The reason for the apparent inappropriate prescribing of ICS as first-line therapy may lie, at least in part, in the discrepancy between recommended use of ICS+LABA combinations in clinical guidelines and the actual approved indications for these combinations. GOLD recommend that ICS+LABA be reserved for patients with GOLD group $\mathrm{C}$ or $\mathrm{D}^{3}$ However, the licensed indication for these combination products is for patients with severe COPD with exacerbations. Consequently, ICS+LABA are approved for use only in a subset of patients classed as GOLD group $C$ or $D$ as the majority of these patients experience only infrequent exacerbations. ${ }^{23}$

Implications for future research, policy and practice

Our results have shown that ICS prescribing is common even for patients with comorbidities or a medical history of conditions that might suggest against the use of an ICS, including a history of pneumonia, fractures and diabetes (Type 1 and Type 2). The implications of inappropriate ICS prescribing for patients with pre-existing comorbidities has the potential to increase the risk for infective comorbidities such as pneumonia,21,24-27 and non-infective comorbidities including fractures ${ }^{21,28}$ and worsening glycaemic control among those with diabetes. ${ }^{29,30}$ Consequently, patients who meet guideline criteria for ICS prescription (GOLD group C or D with exacerbations) with regard to their COPD should be evaluated carefully for the presence of 


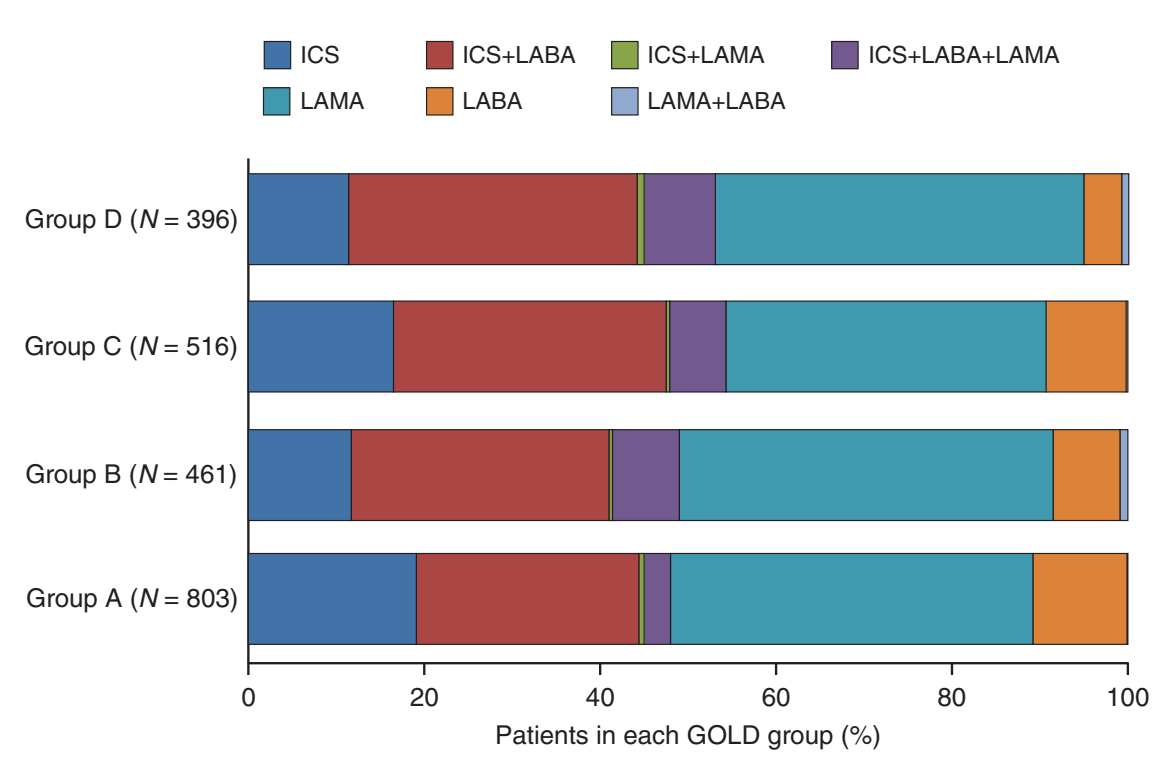

Figure 2. Prescribing pattern for first major therapy class within each GOLD group. GOLD, Global Initiative for Chronic Obstructive Lung Disease; ICS, inhaled corticosteroid; LABA, long-acting beta-agonist; LAMA, long-acting muscarinic antagonist.

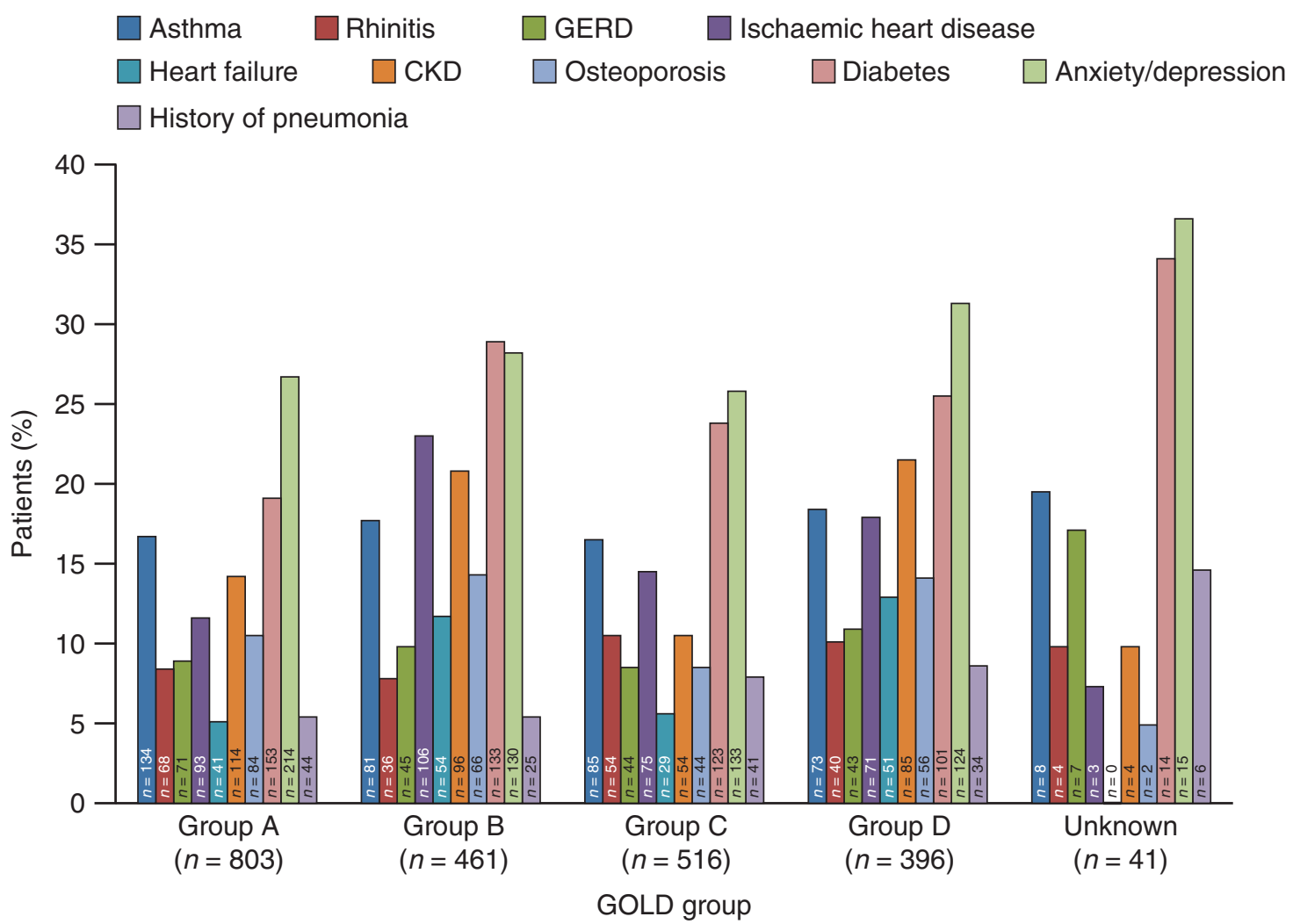

Figure 3. Distribution of comorbidities within each GOLD group. CKD, chronic kidney disease; GERD, gastro-oesophageal reflux disease; GOLD, Global Initiative for Chronic Obstructive Lung Disease.

pre-existing factors such as a history of pneumonia, fracture or Type 2 diabetes. For these patients, the risks of ICS therapy may outweigh the potential benefits. However, in patients with comorbid asthma and COPD, an ICS and bronchodilator combination is likely to be the most appropriate treatment, according to guidelines. A sensitivity analysis excluding those with potential asthma would provide an interesting perspective in a future study. ${ }^{3}$

\section{Conclusions}

In conclusion, there is a need for prescribing to be more in line with current GOLD and NICE guidelines, to ensure the effective and well tolerated treatment of patients with COPD, as the clinical reality of prescribing for patients newly diagnosed with COPD in the UK does not reflect current UK $^{4}$ or international ${ }^{3}$ clinical guidelines. Our data indicate an underuse of bronchodilator therapy and an overuse of ICS therapy in patients in GOLD group 
Asthma $(N=381) \quad \square$ Rhinitis $(N=202) \quad \square \operatorname{GERD}(N=210) \quad \square$ Ischaemic heart disease $(N=348)$

$\square$ Heart failure $(N=175) \quad \square \operatorname{CKD}(N=353) \quad \square$ Osteoporosis $(N=252) \quad \square$ Diabetes $(N=524)$

Anxiety/depression $(N=616) \quad \square$ History of pneumonia $(N=150)$

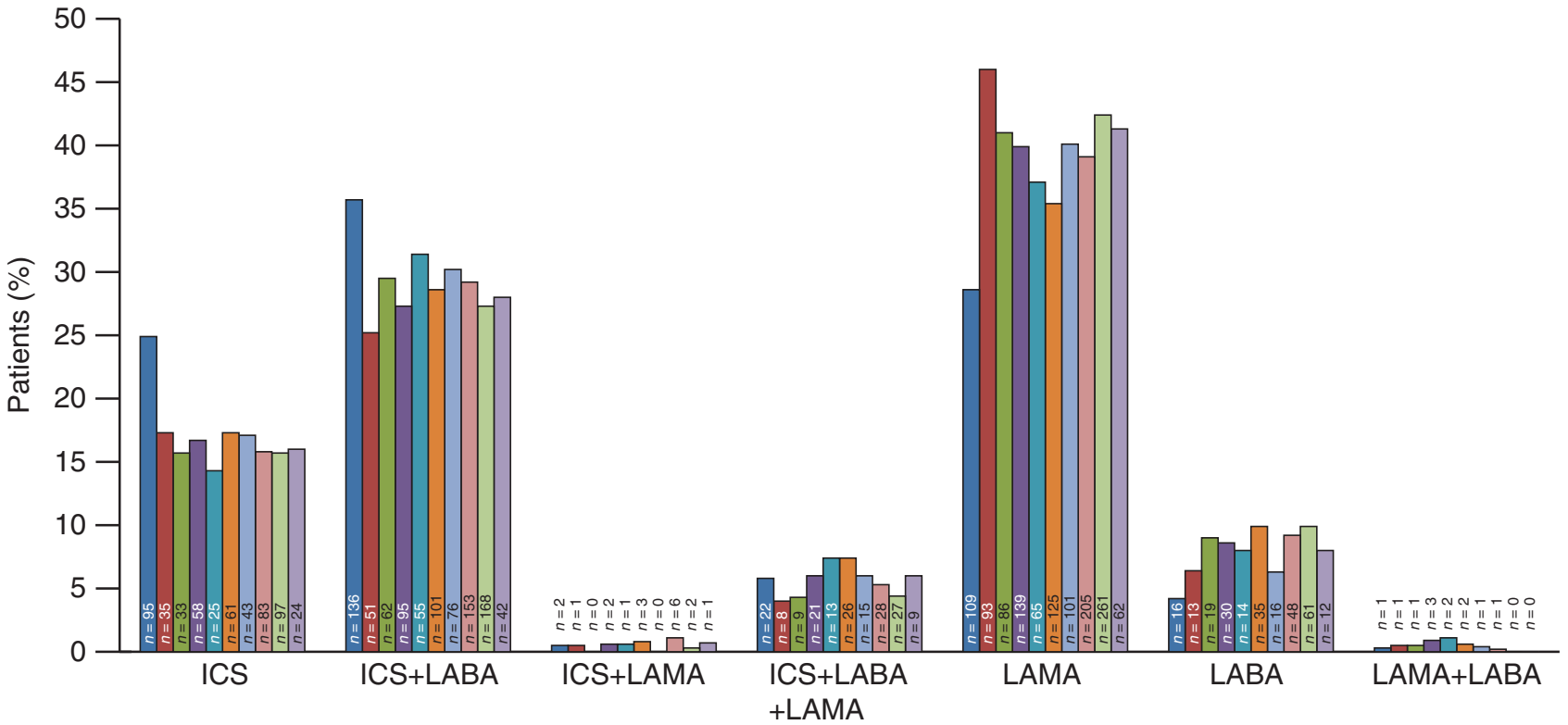

First therapy class

Figure 4. Distribution of comorbidities within each first major therapy class. Proportions are calculated based on the total number of patients reporting each comorbidity and plotted across the first therapy class. CKD, chronic kidney disease; GERD, gastro-oesophageal reflux disease; ICS, inhaled corticosteroid; LABA, long-acting beta-agonist; LAMA, long-acting muscarinic antagonist.

$A$ and B. This would suggest that a substantial proportion of patients with COPD may currently be undertreated while also receiving unnecessary ICS therapy with little clinical benefit and increased risk of associated adverse events. Future research should seek to understand the factors that determine the selection of first major therapy for COPD.

\section{MATERIALS AND METHODS}

This was a retrospective, observational database study. Data were extracted from the Optimum Patient Care Research Database in September 2013. This database includes longitudinal anonymous data extracted from 353 primary care practices offering chronic respiratory services in the UK. The database was approved by the Trent Multi Centre Research Ethics Committee for clinical research use (approval reference 10/H0405/3).

\section{Population for analysis}

Data were extracted for patients with a first prescription for COPD maintenance therapy (ICS, LABA, LAMA or their combination) between 2009 and 2012 and a diagnosis of COPD at or before the date of the first prescription for COPD maintenance therapy. Patients were required to have spirometry recorded within 5 years of COPD diagnosis and at least 2 years of continuous data ( 1 year before and 1 year after the date of the first prescription for COPD maintenance therapy). Patients with a diagnosis of COPD but without sufficient data to determine COPD severity (post-bronchodilator $\mathrm{FEV}_{1}$ ) were excluded from the data set.

\section{Data collection}

The data collection period for the current research was from at least 1 year before, to at least 1 year after, first prescription for therapy, up to a maximum of 4 years. Demographics (including age, body mass index and smoking status), disease characteristics (including severity, therapy before first major COPD therapy, first major COPD therapy, hospitalisation rate, exacerbation rate and questionnaire, and routine modified Medical
Research Council score), comorbidities and history of pneumonia were collected.

\section{Analyses}

Patients were stratified according to lung function-based severity (mild, moderate, severe and very severe) and COPD group (A-D; derived from the modified Medical Research Council score), and the demographic and disease characteristics within each stratum were evaluated. First major therapy class was also determined by GOLD group. History of pneumonia and distribution of comorbidities present at or before the initiation of first maintenance therapy were evaluated by GOLD group. The presence of 'ever' comorbidities of interest (anxiety/depression, diabetes Type 1 and Type 2, osteoporosis, chronic kidney disease (stage 3 (moderate) to 5 (very severe)), heart failure, ischaemic heart disease, gastro-oesophageal reflux disease, rhinitis and asthma (excluding those with an asthma resolved code)) were categorised by first major therapy class.

Statistical analysis

Statistical analyses were descriptive throughout.

\section{ACKNOWLEDGEMENTS}

This research was conducted by Research in Real-Life Ltd (Cambridge, UK), an independent company. Medical writing support was provided by Tracey Lonergan on behalf of Complete Medical Communications and was funded by Almirall S.A.

\section{CONTRIBUTIONS}

DP conducted the analysis and acts as guarantor. DP, MM, IP, MT, JW, JH, KB and DW had full access to and reviewed the data, contributed to the preparation of the manuscript and approved the final version. 


\section{COMPETING INTERESTS}

DP has acted as a consultant for Almirall, Amgen, AstraZeneca, Boehringer Ingelheim, Chiesi, GlaxoSmithKline (GSK), Meda, Mundipharma, Napp, Novartis, Pfizer and Teva. He has received research grants from the UK National Health Service, the British Lung Foundation, Aerocrine, AstraZeneca, Boehringer Ingelheim, Chiesi, Eli Lilly, GSK, Meda, Merck, Mundipharma, Novartis, Orion, Pfizer, Respiratory Effectiveness Group, Takeda, Teva and Zentiva. He owns shares in AKL Ltd, which produced phytopharmaceuticals and owns $80 \%$ of RiRL Ltd and its subsidiary social enterprise Optimum Patient Care. He has received unrestricted funding for investigator-initiated studies from Aerocrine, AKL Ltd, Almirall, Boehringer Ingelheim, Chiesi, Meda, Mundipharma, Napp, Novartis, Orion, Takeda, Teva and Zentiva. MM has received speaker fees from Almirall, Boehringer Ingelheim, Pfizer, AstraZeneca, Chiesi, Esteve, GSK, Menarini, Grifols, Mycomed and Novartis, and has received consulting fees from Almirall, Boehringer Ingelheim, Pfizer, GSK, Gebro Pharma, CLS Behring, Medlmmune, Novartis, Grifols and Nycomed. In the last 5 years, IP has received speaker's honoraria for speaking at sponsored meetings from AstraZeneca, Boehringer Ingelheim, Aerocrine, Almirall, Novartis and GSK, and a payment for organising an educational event for SPRs from AstraZeneca. He has received honoraria for attending advisory panels with Almirall, Genentech, Regeneron, AstraZeneca, Boehringer Ingelheim, GSK, Merck Sharp and Dohme (MSD), Schering-Plough, Novartis, Dey, Napp and Respivert. $\mathrm{He}$ has received sponsorship to attend international scientific meetings from Boehringer Ingelheim, GSK, AstraZeneca and Napp. Neither MT nor any member of his close family has any shares in pharmaceutical companies. In the last 3 years he has received speaker's honoraria for speaking at sponsored meetings or satellite symposia at conferences from the following companies marketing respiratory and allergy products: Aerocrine, AstraZeneca, Boehringer Ingelheim, GSK, MSD and Teva. $\mathrm{He}$ has received honoraria for attending advisory panels with Aerocrine, Almirall, AstraZeneca, Boehringer Ingelheim, Chiesi, GSK, MSD and Novartis. He has received sponsorship to attend international scientific meetings from GSK, AstraZeneca and Mundipharma. He has received funding for research projects from GSK and Almirall. $\mathrm{He}$ is chief medical adviser to the charity Asthma UK, a member of the BTS SIGN Asthma guideline group and the NICE Asthma guideline group. JW has received research grants from GSK, Takeda, Almirall, Novartis, Johnson and Johnson and Vifor Pharma, honoraria for advisory boards for Almirall, Novartis, GSK, Boehringer, Takeda, Johnson and Johnson, Napp, Pfizer and AstraZeneca, and lecture/presentation fees from Almirall, Novartis, GSK, Boehringer and Takeda. JH has received reimbursement for attending symposia, fees for speaking, organising educational events, funds for research or fees for consulting from Almirall, AstraZeneca, Boehringer Ingelheim, Chiesi, Cipla, GSK, MSD, Mundipharma, Novartis and Teva. KB and DW were employees of RiRL Ltd at the time of the study.

\section{FUNDING}

This research was funded by Almirall S.A.

\section{REFERENCES}

1. Health and Safety Executive. Chronic Obstructive Pulmonary Disease (COPD) in Great Britain (2013). Available at www.hse.gov.uk/statistics/causdis/copd/. Accessed on 11 October 2015.

2. National Institute for Health and Care Excellence. NICE pathways. COPD. Available at http://pathways.nice.org.uk/pathways/chronic-obstructive-pulmonary-disease\# content=view-node\%3Anodes-referral-for-specialist-advice. Accessed on 11 October 2016.

3. Global Initiative for Chronic Obstructive Lung Disease. Global strategy for the diagnosis, management, and prevention of chronic obstructive pulmonary disease, Available at http://goldcopd.org/global-strategy-diagnosis-management-preven tion-copd-2016/. Accessed on 11 October 2016.

4. National Clinical Guideline Centre. Chronic obstructive pulmonary disease: management of chronic obstructive pulmonary disease in adults in primary and secondary care. Available at http://guidance.nice.org.uk/CG101/Guidance/pdf/ English. Accessed on 11 October 2016.

5. Price, D., Yawn, B., Brusselle, G. \& Rossi, A. Risk-to-benefit ratio of inhaled corticosteroids in patients with COPD. Prim. Care Respir. J. 22, 92-100 (2013).

6. Anton, E. How and when to use inhaled corticosteroids in chronic obstructive pulmonary disease? Expert Rev. Respir. Med. 7(2 Suppl), 25-32 (2013).

7. Sabroe, I., Postma, D., Heijink, I. \& Dockrell, D. H. The yin and the yang of immunosuppression with inhaled corticosteroids. Thorax 68, 1085-1087 (2013).

8. Jones, R. C., Dickson-Spillmann, M., Mather, M. J., Marks, D. \& Shackell, B. S. Accuracy of diagnostic registers and management of chronic obstructive pulmonary disease: the Devon primary care audit. Respir. Res. 9, 62-69 (2008).

9. Corrado, A. \& Rossi, A. How far is real life from COPD therapy guidelines? An Italian observational study. Respir. Med. 106, 989-997 (2012).

10. Drivenes, E., Ostrem, A. \& Melbye, H. Predictors of ICS/LABA prescribing in COPD patients: a study from general practice. BMC Fam. Pract. 15, 42 (2014).

11. Jebrak, G. [COPD routine management in France: are guidelines used in clinical practice?]. Rev. Mal. Respir. 27, 11-18 (2010).

12. Jochmann, A. et al. General practitioner's adherence to the COPD GOLD guidelines: baseline data of the Swiss COPD Cohort Study. Swiss Med. Wkly. 140 (w13053), 1-8 (2010).

13. Price, D. et al. Management of COPD in the UK primary-care setting: an analysis of real-life prescribing patterns. Int. J. Chron. Obstruct. Pulmon. Dis. 9, 889-904 (2014).

14. Di Martino, M. et al. Use patterns of long-acting bronchodilators in routine COPD care: the OUTPUL study. COPD 11, 414-423 (2014).

15. Fitch, K., Iwasaki, K., Pyenson, B., Plauschinat, C. \& Zhang, J. Variation in adherence with Global Initiative for Chronic Obstructive Lung Disease (GOLD) drug therapy guidelines: a retrospective actuarial claims data analysis. Curr. Med. Res. Opin. 27, 1425-1429 (2011)

16. Miravitlles, M. et al. Use of spirometry and patterns of prescribing in COPD in primary care. Respir. Med. 101, 1753-1760 (2007).

17. White, P., Thornton, H., Pinnock, H., Georgopoulou, S. \& Booth, H. P. Overtreatment of COPD with inhaled corticosteroids--implications for safety and costs: cross-sectional observational study. PLOS ONE 8, e75221 (2013).

18. Brusselle, G. et al. The inevitable drift to triple therapy in COPD: an analysis of prescribing pathways in the UK. Int. J. Chron. Obstruct. Pulmon. Dis. 10, 2207-2217 (2015).

19. Kerkhof, M., Freeman, D., Jones, R., Chisholm, A. \& Price, D. B. Predicting frequent COPD exacerbations using primary care data. Int. J. Chron. Obstruct. Pulmon. Dis. 10, 2439-2450 (2015).

20. Calverley, P. M. et al. Salmeterol and fluticasone propionate and survival in chronic obstructive pulmonary disease. N. Engl. J. Med. 356, 775-789 (2007).

21. Loke, Y. K., Cavallazzi, R. \& Singh, S. Risk of fractures with inhaled corticosteroids in COPD: systematic review and meta-analysis of randomised controlled trials and observational studies. Thorax 66, 699-708 (2011).

22. Singh, S. \& Loke, Y. K. Risk of pneumonia associated with long-term use of inhaled corticosteroids in chronic obstructive pulmonary disease: a critical review and update. Curr. Opin. Pulm. Med. 16, 118-122 (2010).

23. Agusti A. et al. Characteristics, stability and outcomes of the 2011 GOLD COPD groups in the ECLIPSE cohort. Eur. Respir. J. 42, 36-646 (2013).

24. DiSantostefano, R. L. et al. Risk of pneumonia with inhaled corticosteroid versus long-acting bronchodilator regimens in chronic obstructive pulmonary disease: a new-user cohort study. PLOS ONE 9, e97149 (2014).

25. Mattishent, K. et al. Meta-review: adverse effects of inhaled corticosteroids relevant to older patients. Drugs 74, 539-547 (2014).

26. Kew, K. M. \& Seniukovich, A. Inhaled steroids and risk of pneumonia for chronic obstructive pulmonary disease. Cochrane Database Syst. Rev. 3, CD010115 (2014).

27. Suissa, S., Patenaude, V., Lapi, F. \& Ernst, P. Inhaled corticosteroids in COPD and the risk of serious pneumonia. Thorax 68, 1029-1036 (2013).

28. Lee, T. A. \& Weiss, K. B. Fracture risk associated with inhaled corticosteroid use in chronic obstructive pulmonary disease. Am. J. Respir. Crit. Care Med. 169, 855-859 (2004).

29. Rogliani, P., Calzetta, L., Segreti, A., Barrile, A. \& Cazzola, M. Diabetes mellitus among outpatients with COPD attending a university hospital. Acta Diabetol. 51, 933-940 (2014).

30. Slatore, C. G., Bryson, C. L. \& Au, D. H. The association of inhaled corticosteroid use with serum glucose concentration in a large cohort. Am. J. Med. 122, 472-478 (2009).

This work is licensed under a Creative Commons Attribution 4.0 International License. The images or other third party material in this article are included in the article's Creative Commons license, unless indicated otherwise in the credit line; if the material is not included under the Creative Commons license, users will need to obtain permission from the license holder to reproduce the material. To view a copy of this license, visit http://creativecommons.org/licenses/ by/4.0/

(c) The Author(s) 2016 